\title{
합병기업의 기업문화 구성요소가 조직유효성에 미치는 영향 A Study on the Influence of Factors of Corporate Culture for the Organizational Effectiveness in Merger Enterprise
}

\author{
박근석 ${ }^{1} \cdot$ 김종림 $^{2} \cdot$ 남기은 $^{3}$ \\ Kun-Suk Park', Jong-Lim Kim², and Ki-Eun $\mathrm{Nam}^{3}$ \\ (Received August 31, 2010 / Revised October 5, 2010 / Accepted October 11, 2010)
}

\begin{abstract}
요 약
합병기업에 있어 기업문화의 통합은 $\mathrm{M \& A}$ 의 성공 여부를 좌우하는 중요한 변수로 간주되고 있다. 본 연구는 합병기업의 기업문화 통합과 조직유효 성과의 관계에 대한 선행연구를 근거로 개념적 연구모형을 수립하고, 이의 타당성을 검증하기 위하여 Pascale \& Athos 및 Peters \& Waterman이 제시한 7 개의 기업문화 구성요소와 조직유효성의 관련성에 관한 연구가설을 설정하였다. 가설검증을 위하여 다중회귀분석을 이용한 결과 다음과 같은 사실을 발견하였다. 첫째, 합병기업의 기업문화 구성요소가 조직유효성 중 직무몰입에 미치는 영향은 기업문화의 모든 구성요소가 유의한 영향 을 미치는 것으로 나타났다. 둘째, 합병기업의 기업문화 구성요소가 조직유효성 중 직무만족에 미치는 영향은 기업문화 구성요소 중 공유가치를 제외한 모든 요인이 유의한 영향을 미치는 것으로 나타났다. 셋째, 합병기업의 기업문화 구성요소가 조직유효성 중 조직융합에 미치는 영향은 기업문 화 구성요소 중 사업능력 및 기술력을 제외한 모든 요인이 유의한 영향을 미치는 것으로 나타났다. 본 연구는 기업문화 구성요소 변수를 확인하고 그것이 조직유효성에 미치는 영향을 실증적으로 검증한 탐색적 연구라는데 그 의의가 있다고 할 수 있다.
\end{abstract}

주제어 기업문화, 구성요소, 합병기업, 조직유효성, 직무몰입, 직무만족, 조직융합

\begin{abstract}
Integrating corporate culture in a merger enterprise is considered as one of the most important variables to decide M\&A success. This study established a conceptional model according to the preceding study on integrating corporate culture and organizational effectiveness, and formulated a hypothesis on the interrelation between a seven factors of corporate culture proposed by Pascale \& Athos and Peters \& Waterman and organizational effectiveness. The result of applying multi-regression analysis to test the hypothesis is as follows; firstly, all of a merger enterprise's cultural factors have meaningful influence on job involvement among organizational effectiveness; secondly, all of them have sincere influence on job satisfaction among organizational effectiveness except shared value; and thirdly, all of them except skill have significant influence on organizational harmony among organizational effectiveness. This is a significant empirical and exploratory study to ascertain the variables of corporate culture factors, and to verify their effects on organizational effectiveness.
\end{abstract}

Key words Corporate culture, Factor, Merger enterprise, Organizational effectiveness, Job involvement, job satisfaction, Organizational harmony

\section{1. 서 론}

21세기 급변하는 경영환경과 경쟁환경 하에서 기업이 지 속가능한 기업으로 유지 발전하기 위해서는 경쟁우위를 점유 할 수 있는 생존전략을 체계적으로 추진해 나아가야 한다. 기 업의 생존과 발전을 위한 경쟁우위 확보는 개별기업이 가지 고 있는 경영자원만으로는 한계가 있으므로 기업들은 전략적
제휴를 추진하여 경영자원의 한계를 극복하고 성과를 극대화 하며, 기업의 유연성을 확보하고자 노력하고 있다. 이러한 전 략적 제휴 중에서도 가장 많이 추진하는 형태가 기업간 인수 합병(M\&A)이다.

그러나 이러한 $\mathrm{M \& A}$ 는 해당 기업 상호간에 경영자원, 기 술, 기업문화, 제도, 시스템, 조직구조 등에서 많은 차이를 나 타내므로, 이를 효율적으로 통합시키기 위한 활동이 지속적

1) 한국토지주택공사 토지주택연구원 수석연구원(gracepks@lh.or.kr)

2) 한국토지주택공사 토지주택연구원 선임연구위원(교신저자: jrkim@lh.or.kr)

3) 한국토지주택공사 토지주택연구원 연구원 
으로 이루어져야 한다. 특히 최근에는 기업문화 통합에 대한 관심이 높아지고 있다. 이는 M\&A 기업이 합병 전에 자기 기 업만의 독특한 기업문화를 유지하고 있었으나 M\&A로 인한 기업문화의 충돌로 인해 조직구성원의 심리상태가 불안해지 고, 조직유효성이 저하되어 $\mathrm{M} \& \mathrm{~A}$ 에 따른 시너지 효과를 창 출하지 못하고 성과를 내지 못하는 결과를 발생할 수도 있기 때문이다(박경문·최명범, 2002).

즉, 합병기업의 기업문화 통합은 그 조직의 성패를 결정짓 는 중요한 요인이 될 수 있기 때문에 조직이 통합되면 새로 운 기업문화의 창출을 통한 조직융합이 필요하고, 많은 기업 들은 이를 위해 노력하고 있다. 그러나 기업문화는 하나의 요 소로만 구성되는 것이 아니라 여러 가지 구성요소를 가지고 있기 때문에 이들 각각의 요인에 대한 통합 노력이 필요하다.

이에 따라 본 연구는 합병기업의 문화적 통합의 중요성에 초점을 맞추어 실제 2009년 10월 공기업 선진화의 일환으로 통합된 공기업의 조직구성원들을 대상으로 Peters \& Waterman (1982) 등이 제시한 공유가치, 전략, 구조, 관리시스템, 구성 원, 기술, 리더십스타일의 7 개 기업문화 구성요소를 중심으 로 이들 구성요소들의 통합이 조직유효성에 어떠한 영향을 미치는지를 실증분석을 통해 규명하고자 한다.

\section{2. 이론적 배경}

\section{1 합병기업에서 기업문화의 의의}

기업문화는 외부환경에 대한 적응과 조직내부 통합의 문제 를 해결하기 위하여 구성원들에 의해 창조, 발전되어 학습되 는 기본가정으로서 조직구성원들에 의해 공유된 가치(value), 신념(beliefs), 규범(norms)의 체계로 정의된다(Schein, 2004). 그러나 이러한 정의는 모든 조직에 일괄적으로 적용된다고는 할 수 없으며, 많은 기업문화 연구자들은 각자의 관점이나 분 석 수준에 따라 조금씩 상이하게 기업문화를 정의하고 있다.

기업문화는 신념이나 가치의식과 같은 것으로 눈에 확연 히 보이는 쉽게 관찰할 수 있는 속성의 것이 아니다. 그러나 이렇게 눈에 보이지 않는 문화와 관련된 쟁점이 눈에 두드러 지게 보이는 시점이 있는데, 각기 다른 기업이 하나로 통합되 는 때이다. 서로 다른 문화 속에 생활하던 구성원들은 두 기 업의 통합으로 인해 기업의 철학이나 분위기의 변화 같은 새 로운 경험을 하게 된다. 이러한 상황에서 미처 지각하지 못했 던, 자신이 그동안 경험했던 기존기업의 특성이 무엇이었는 지 더 확연히 깨닫게 되고 새로운 문화와 접하게 되어 혼란 을 겪게 되는 것이다.

Schein(2004)은 이렇게 서로 다른 문화가 결합하게 되었을 때 일반적으로 나타나는 현상을 다음과 같은 세 가지의 양상 으로 설명하였다(딜로이트컨설팅코리아 역, 2006). 첫 번째 상황은 두 기업이 개별적 정체성을 유지하면서 마치 거대 복 합기업과 같이 두 문화가 분리된 상태로 존속하는 경우이다.
통합은 했지만 기존의 회사만 인정할 뿐 새로운 협력의 길로 나아가지 못하는 경우이다. 두 번째 상황은 하나의 문화가 다 른 문화를 지배하는 것이다. 이러한 경우는 큰 회사가 작은 회사를 인수하는 경우 두드러지는 현상이다. 지배받는 입장 에 속하게 된 구성원들은 강제로 새로운 문화를 배워야하는 상황에 처하게 되는 것이다. 세 번째는 두 문화가 융합하는 것 이다. 두 문화의 장점을 통합하는 융합현상이 가장 장려되지 만 실상 일어나는 일은 대게 더욱 복잡하고 애매모호하다. 더 욱이 두 문화의 융합은 자연스럽게 나타나기 보다는 통합된 조직에 새로운 문화구축을 위한 절차를 수립하고 문화통합을 위한 노력을 통해서만 비로소 나타나기 때문에 두 문화의 장 점만을 채택하면 된다는 단순한 논리를 적용할 수가 없다.

통상적으로 2 개의 기업이 결합되는 경우 시스템, 기업의 새로운 이름 등 눈에 보이는 해결해야 할 당면한 문제들이 너무나도 많기 때문에 눈에 보이지 않는 문화와 관련된 쟁점 을 해결하기 위해 투자된 시간은 부족한 경우가 많다. 그러나 기업문화가 해당 기업에 어떠한 영향을 미치는지에 대해 구 체적으로 접근해 본다면 문화의 통합 역시 당면한 시급한 문 제임을 알 수 있다.

기업문화는 기업의 총체적 특성으로서, 내적으로는 구성원 들의 공통된 가치관과 사고방식(또는 기본전제)이 그리고 외 적으로는 그들의 실제 행동이 중요한 부분을 차지하고 있다. 이와 같이 기업문화를 실행하는 주체는 어디까지나 구성원들 인 만큼, 조직은 구성원들의 가치중심적 사고방식과 행동에 의해 강한 기업문화가 유지될 수 있다. 따라서 높은 기업성과 에 기여하는 핵심가치의 도출은 물론, 이를 구성원들의 공유 가치로 의식화시키고, 그들의 가치중심적 행동을 조장하여 체질화시키도록 인적자원 관리제도를 개선하고, 관리자는 리 더십을 통해 이를 뒷받침하는 것이 중요하다. 그리고 이러한 활동들이 모두 시너지로 작용하여 전체적으로 강한 기업문화 를 유지할 수 있을 때 기업의 경쟁력도 동시에 향상되는 것 으로 될 수 있다(이학종, 2008).

합병기업에 있어 기업문화의 통합과 그 역할이 중요하다는 것은 다양한 선행연구들에서 제시되고 있다. Cary \& Mallory (1998)는 합병 시 양 조직의 문화적 적합성 부족으로 조직융 합이 안될 경우에는 합병 후 수익률이 낮아지나, 문화적 적합 성이 높아져 조직융합이 된 경우에는 생산성이 크게 향상됨 을 입증하였다. 또한 현대경제연구원(1999)은 기업합병이 실 질적인 경쟁력 향상으로 이어지기 위해서는 문화, 가치관 등 소프트한 측면의 변화가 수반되어야 한다고 제시하였다. Schweight \& Weber(1993)는 두 회사가 융합이 되려면 서로 다 른 기업문화, 그리고 관리체제와 절차들이 하나로 되어야 한 다고 하였다(황성돈 외, 2008 , 재인용). 즉, 합병기업의 기업 문화와 함께 관리체제와 절차 통합의 중요성을 말하고 있다.

결론적으로 선행연구결과들은 내용을 종합해보면, 기업의 합병은 통합과정에서 조직원들이 업무상으로나 정서상으로 
혼란을 겪기 때문에 조직성과를 향상시키는 데 있어 제약요 인 내지 장애요인으로 작용할 가능성이 높다는 점을 시사하 고 있다. 아울러 합병과정에서의 혼란을 조속히 극복하고 조 직성과를 증대시키기 위해서는 문화의 통합과 더불어 관리체 제 등의 제도와 시스템의 통합이 필요하다는 점을 시사하고 있다.

\section{2 기업문화의 구성요소}

앞서 언급한 바와 같이 기업문화는 신념이나 가치의식과 같은 것으로 눈에 확연히 보이는 쉽게 관찰 할 수 있는 속성 의 것이 아니다. 따라서 기업문화를 구성하고 있는 관찰할 수 있는 속성의 요소들을 살펴봄으로 기업문화를 가시화할 수 있다. 또한 이를 통해 문화에 대한 이해도 더욱 증진될 수 있 을 것이다. 기업문화의 구성요소에 대해서는 학자들마다 조 금씩 견해의 차이가 있는데 기업문화의 주된 구성요소가 무 엇이고 어떻게 문화를 형성되는지 살펴보고자 한다.

기업문화의 7S 구성요소는 Pascale \& Athos(1981)의 일본 기업 연구와 Peters \& Waterman(1982)의 미국 우수기업 연구 에서 제시되었는데, 기업문화를 구성하는 일곱 요소 모두가 $\mathrm{S}$ 자로 시작되기 때문에 7'S라고 명명하고 있다. 이 들 구성요 소를 요약하면 다음과 같다.

\subsection{1 공유가치(Shared Value)}

기업문화의 첫째 구성요소는 기업체의 구성원들 모두가 공동으로 소유하고 있는 가치관과 이념, 그리고 전통가치와 기업의 기본목적 등 기업체의 공유가치이다. 그림 1 에서 보 는 바 와 같이 공유가치는 다른 기업문화 구성요소에 지배적

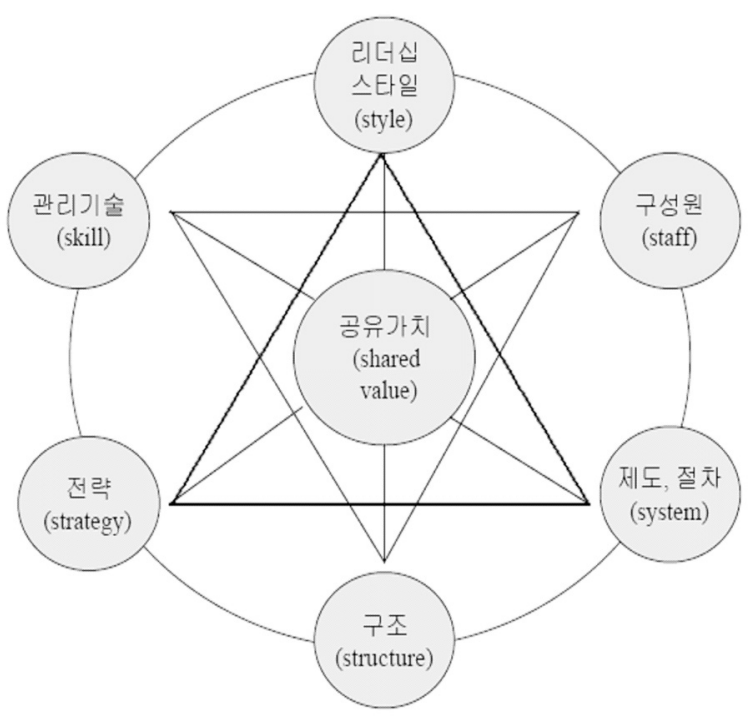

그림 1. 기업문화의 $7 \mathrm{~S}$ 구성요소

자료: Pascale \& Athos, 1981, p.203: Peters \& Waterman, 1982, p.10.
인 영향을 줌으로써 기업문화 형성에 가장 중요한 위치를 차 지한다. 또한 구성원들 사이에서 조직의 존속이나 성공의 근 본적 요인이라고 인식되어 조직유효성에 큰 영향을 미친다.

\subsection{2 전략(Strategy)}

기업문화의 둘째 구성요소는 기업의 장기 방향과 기본 성 격을 결정하는 경영전략으로서, 기업의 장기적인 목적과 계 획, 그리고 이를 달성하기 위한 장기적인 자원배분패턴을 포 함한다. 기업의 전략은 기업의 이념과 목적 그리고 기본가치 를 중심으로 이를 달성하기 위한 기업체 운영에 장기적인 방 향을 제공함으로써 다른 기업문화 구성요소에 많은 영향을 준다.

\subsection{3 구조(Structure)}

구조는 기업의 전략을 수행하는데 필요한 틀로서 조직주 조와 직무설계, 그리고 권한관계와 방침 등 구성원들의 역할 과 그들 간의 상호관계를 지배하는 공식요소를 포함한다. 따 라서 구조는 관리시스템과 더불어 구성원들의 일상 업무수행 과 행동에 많은 영향을 준다.

\subsection{4 관리시스템(System)}

기업문화를 구성하는 또 하나의 중요요소는 기업경영의 의사결정과 일상운영에 틀이 되는 관리제도와 절차 등 각종 시스템이다. 따라서 시스템은 기업의 기본가치와 일관성 있 고 장기적인 전략목적달성에 적합한 보상제도와 인센티브, 경영정보와 의사결정시스템, 경영계획과 목표설정시스템, 결 과측정과 조정·통제 등 경영 각 분야의 관리제도와 절차를 포 함한다.

\subsection{5 구성원(staff)}

기업문화는 기업 구성원들의 행동을 통하여 실제로 나타 난다. 따라서 구성원은 기업문화의 구성요소로서 기업의 인 력구성과 구성원들의 능력, 전문성, 가치관과 신념, 욕구와 동기, 지각과 태도 그리고 그들의 행동패턴 등을 의미한다. 구성원들의 가치관과 행동은 기업이 의도하는 기본가치에 의 하여, 그리고 인력구성과 전문성은 기업이 추구하는 경영전 략에 의하여 각각 많은 영향을 받는다.

\subsection{6 기술(skill)}

기술 또한 기업문화를 형성하고 있는 중요요소로서 각종 기계.장치와 컴퓨터 등 생산 및 정보처리 분야의 물리적 하드 웨어는 물론, 이를 사용하는 소프트웨어 기술을 포함한다. 그 뿐 아니라 구성원들에 대한 동기부여와 행동 강화, 갈등관리 와 변화관리, 목표관리와 예산관리 등 기업경영에 적용되는 관리기술과 기법도 포함한다. 


\subsection{7 리더십 스타일(Style)}

기업문화의 마지막 구성요소는 구성원들을 이끌어 나가는 전반적인 리더십 스타일로서 구성원들의 행동조성은 물론, 그들 간의 상호관계와 조직분위기에 직접적인 영향을 주는 중요 요소이다. 기업의 개방적, 참여적, 온정적, 유기적 성격 등은 일상경영에서 적용되는 관리 및 리더십 스타일로부터 많은 영향을 받으면서 형성된다.

이상의 7 가지 요소들은 밀접하게 상호연결되고 상호의존 적인 관계를 이루면서 기업의 독특한 특성을 나타내며 기업 문화를 형성한다. 이들 요소간의 상호연결성과 상호의존성이 높을수록 강하고 뚜렷한 기업문화가 형성되고, 상호연결성과 상호의존성이 결여될수록 약하고 애매하며 일관성이 없는 기 업문화가 형성된다. 따라서 바람직한 기업문화의 개발은 이 들 요소를 바람직한 방향으로 개발함으로써 이루어질 수 있 다. 그리고 개별적인 관점으로 각각의 요소를 분석하는 것을 넘어서 전체적인 문화적 관점에서 이해될 때 기업문화에 대 한 총체적인 이해가 이루어 질 수 있다.

\section{3 기업문화와 조직유효성}

\subsection{1 조직유효성}

경영학 연구 분야에서는 경영성과를 측정하기 위한 대용변 수로서 조직성과를 이용하는데 이는 조직유효성(effectiveness) 과 조직효율성(efficiency)으로 구성된다. 조직유효성이 목표 에 대한 달성 정도라면, 조직효율성은 목표달성에 기여한 정 도라고 할 수 있다.

조직유효성에 대한 정의 관점에서 볼 때 이에 대한 선행연 구는 다양하게 이루어지고 있다. Steers(1975)는 15개의 조직 유효성 평가기준을 사용빈도순으로 제시하였는데, 적응성 또 는 탄력성, 생산성, 만족성, 수익성, 자원획득, 환경통제력, 개 발성, 능률성 등이다. Campbell(1977)은 30개의 평가기준을 사용빈도와 관계없이 제시하였는데 전체적 효과성, 생산성, 능률성, 수익성, 질, 사고율, 성장, 결근률, 이직률, 직무만족, 동기부여, 사기, 통제력 등이다(민경호·이병석, 2005). 박경 문·최명범(2002)은 합병기업의 조직문화와 조직유효성과의 연구에서 조직유효성 요인을 이직의도, 직무만족, 조직몰입, 스트레스로 정의하고 있다.

이와 같이 조직유효성의 요소 내지 측정항목은 학자들 간 에 일치되지 못하는 실정이다. 그러나 일반적으로 조직유효 성의 평가항목은 양과 질, 시간과 비용의 기준으로 고찰하여 측정한다. 양적 기준은 생산성, 이윤, 재무성과와 같이 직접 측정할 수 있는 기준이며, 질적 기준은 구성원의 태도나 인식 의 조사를 통해 얻을 수 있는 기준으로서 개인수준에서의 직 무성과, 조직수준에서 적응성, 사기 등이 있다(박민생, 2006). 고종식(1999)은 기업문화 유형과 조직유효성에 관한 연구에 서 조직유효성 변수를 직무만족과 조직몰입으로 측정하였다.
본 연구에서는 선행연구에서 빈도있게 다루어졌던 조직유 효성의 요소를 개인차원과 조직차원으로 구분하여 파악해 보 고자 한다. 즉, 개인차원에서 직무성과는 직무몰입, 직무만족 이라는 요인으로, 조직차원에서는 조직적응성이라는 요인을 통합기업의 특성에 맞게 조직융합이라는 요인으로 측정하고 자 한다.

\subsection{2 기업문화 구성요소와 조직유효성과의 관계}

기업문화는 구성원의 사고와 행동에 영향을 주는 요소로 서 조직유효성에 많은 영향을 미치고 있지만 조직유효성과 직접 관련이 있다는 연구는 상대적으로 적다. 기업문화 관련 많은 연구들이 기업문화가 얼마나 강하냐에 따라 기업이 경 쟁력을 가진다는 또는 어떤 요인을 통해 강해지는가에 초점 이 맞춰져 있기 때문이다. 즉, 기업문화의 구성과 개발에 중 점을 두는 연구들이 많은 편이다. 몇 몇 경영학자들이 연구한 기업문화와 조직유효성과의 관련성에 대한 견해를 고찰해보 면 다음과 같다.

Deal \& Kennedy(1982)는 기업문화는 강하던 약하던 조직 에 큰 영향력을 미치므로 조직성과에도 큰 영향을 미친다고 하였다. 또한 강한 기업문화를 구축하기 위해서는 조직 내에 영웅과 같은 존재가 있어 문화를 이끌고 가야 한다고 하였다. 이러한 영웅은 $\mathrm{CEO}$ 일 가능성이 매우 크며, 앞서 연구한 기업 문화와 리더쉽과의 관계에 대한 연구들(박경문·최명범, 2001 : 김세영, 1990 등)은 $\mathrm{CEO}$ 의 리더쉽은 기업문화의 구성 및 강화에 큰 역할을 한다고 규명하고 있다.

신유근(1985)은 기업문화의 확립정도가 높은 기업이 조직 성과가 높게 나타나고, 기업문화의 확립정도를 높게 인식하 는 기업체가 낮게 인식하는 기업체보다 높은 조직성과를 나 타낸다고 주장하였다. 여기서 기업문화의 확립정도는 핵심가 치에 대한 조직원들의 공유 및 실천에 대한 것을 의미하며, 핵심가치의 공유는 기업문화의 구성에 중요한 역할을 하는 요소임을 알 수 있다.

합병기업은 통상 PMI(Post Merger \& Integration) 과정을 거치게 되는데 이 과정에서 제도 및 시스템 통합 작업을 거 치게 된다. 이러한 작업을 거치지 않게 되면 구성원들은 통합 에 따른 혼란과 함께 제도상의 혼란을 더하게 되어 기업이 어려움에 직면하게 된다. 따라서 제도 및 시스템의 통합작업 은 중요성이 크다 할 수 있으며 특히, 승진, 성과보상, 복지 등의 인사제도의 통합은 중요성과 함께 파급효과가 매우 크 다고 할 수 있다.

기업문화와 조직성과와의 관계에 대한 선행연구들을 종합 해보면, 합병기업과 같은 서로 다른 두 기업이 합쳐진 기업에 서는 기업문화가 잘 융합된 기업이 그렇지 않은 기업보다 조 직성과 향상에 더 큰 영향을 미친다는 것을 알 수 있다. 그러 나 이러한 기업문화와 조직유효성의 관계에 대한 대부분의 선행연구들은 기업문화의 특성, 즉 기업문화의 강도 내지는 
특징이 조직유효성에 미치는 영향을 중심으로 수행되었고, 세부적으로 기업문화 구성요소들과 조직유효성에 대한 영향 관계를 규명한 연구는 거의 없다. 다만 부분적으로 $\mathrm{CEO}$ 의 리더십이 조직유효성에 미치는 영향에 대한 연구가 제한적으 로 수행되었을 뿐이다.

따라서 합병기업의 기업문화 통합이 조직유효성에 미치는 영향을 분석하기 위해 구체적으로 기업문화 구성요소가 조직 유효성에 미치는 영향을 분석하는 것은 새로운 접근이라 할 수 있다.

\section{3. 연구의 설계}

\section{1 연구모형}

상술한 선행연구에 근거하면, 합병기업에 있어 문화통합이 중요하며 문화통합의 정도와 형태에 따라 조직유효성에 차이 가 날 수 있다. 또한 문화통합을 위한 조직구성원들의 노력과 의지에 의해 조직문화의 통합성패가 결정된다. 여기서 조직 구성원들의 노력과 의지는 기업문화를 구성하고 있는 각 구 성요소별 통합 내지는 통합에 따른 개선노력을 말한다. 본 연 구에서는 공기업선진화 정책의 일환으로 2009년 10월 1일부 로 통합된 공기업의 조직구성원들을 대상으로 통합기업의 기 업문화 구성요소들이 조직유효성에 어떠한 영향을 미치는가 를 분석하고자 한다.

합병기업의 기업문화를 통합시키기 위해서는 가치나 신념 등의 의식적 요소의 통합도 중요하지만 기업문화의 구성요소 에서 살펴본 바와 같이 기업문화를 구성하는 제도와 시스템 등이 전반적으로 통합될 때 기업문화의 통합도 달성되는 것 이다. 합병기업에서 기업문화의 통합을 달성하기 위해서는 공유가치, 전략의 통합, 조직의 통합, 기술의 통합, 리더쉽, 구성원의 통합, 제도 및 시스템의 통합 등 어느 한 가지 요인 도 소홀히 할 수 없는 요인들이다. 그러나 기업의 합병 후 통 합과정은 장기간이 소요될 뿐 만 아니라 투자재원, 구성원간

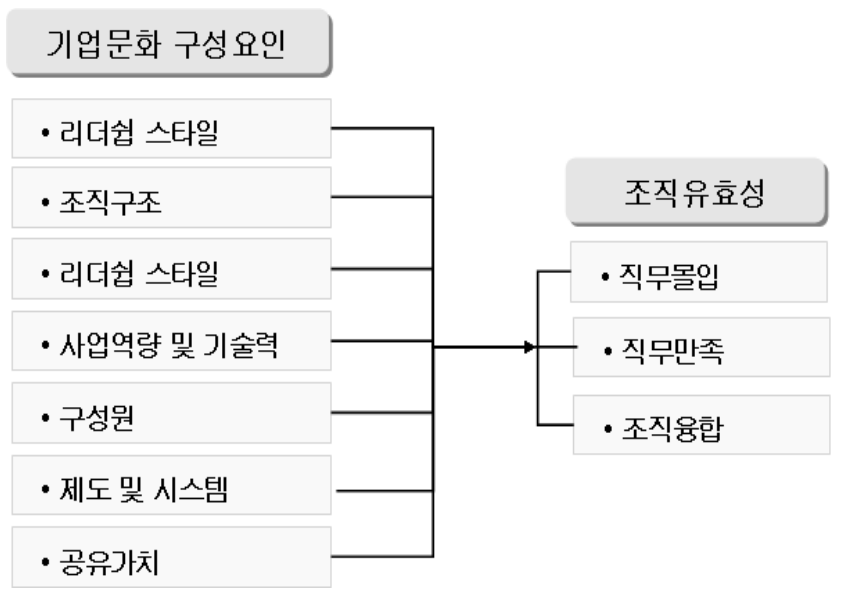

그림 2. 연구모형
의 갈등 등 많은 제약요인으로 인해 구성요소별로 통합의 완 성도는 그 내용과 수준에 있어 상당히 많은 차이가 존재한다. 이는 합병 이후에도 상당기간 승진제도나 급여제도를 이원적 으로 운영하는 민간기업의 통합사례에서도 증명되고 있다. 따라서 본 연구에서는 합병기업에 있어 기업문화가 조직유효 성에 영향을 미치나 그 영향 정도와 방향은 조직유효성에 차 별적으로 영향을 미칠 것을 가정하여 이들의 관계를 그림 2 와 같은 연구모형으로 설정하였다.

\section{2 연구가설}

본 연구에서는 통합기업의 기업문화의 구성요소 그리고 조직유효성에 관한 선행연구를 토대로 설정한 개념적 연구모 형의 타당성을 검증하기 위하여 통합기업의 기업문화 구성요 소와 조직유효성의 관련성에 관한 연구가설을 다음과 같이 설정하고자 한다.

가설1. 기업문화 구성요소는 조직구성원의 직무몰입에 상 이한 영향을 미칠 것이다.

가설2. 기업문화 구성요소는 조직구성원의 직무만족에 상 이한 영향을 미칠 것이다.

가설3. 기업문화 구성요소는 조직구성원의 조직융합에 상 이한 영향을 미칠 것이다.

\section{3 변수의 조작적 정의}

\subsection{1 통합기업의 기업문화 구성요소}

기업문화 구성요소는 Pascale \& Athos(1981)와 Peters \& Waterman(1982)의 모형에 따라 7가지 구성요소를 조사기업 의 특성에 맞도록 변형하여 전체 특성을 제시한 문항으로 구 성하였다. 기업문화 7 가지 구성요소에 대한 조작적 정의는 다음과 같다.

(1) 경영전략 : 기업의 장기방향과 기본 성격을 결정하는 것으로서 기업의 장기적인 목적과 계획 그리고 이를 달성하기 위한 장기적인 자원배분 패턴을 포함한다. 본 연구에서는 미래 발전 모습인 비전의 명확한 설정, 비전달성을 위한 경영목표 명확한 설정, 환경변화에 적절히 대응하는 경영전략 수립 등 3 개 문항으로 측정 하였다.

(2) 조직구조 : 조직구조와 직무설계 그리고 권한관계와 운 영 등 구성원의 역할을 지배하는 공식적 요소이다. 본 연구에서는 사업기능과 역할수행에 적합한 조직설계, 책임과 권한의 적합한 배분, 환경변화에 유연한 조직구 조와 운영체계, 효율적 사업수행을 위한 업무프로세스, 합리적인 인력배치 등 4 개 문항으로 측정하였다.

(3) 리더쉽스타일: 구성원들의 행동조성, 상호관계와 조직 
분위기에 직접적인 영향을 주는 요인이다. 본 연구에 서는 경영진의 리더쉽 발휘, 상하간 의사소통, 직속상 사에 대한 믿음, 상사의 이상적인 리더쉽 보유 등 4개 문항으로 측정하였다.

(4) 기술: 기업의 물리적 하드웨어는 물론 이를 사용하는 소프트웨어를 포함하며, 구성원에 대한 동기부여, 행동 강화, 목표관리 등 경영에 적용되는 관리기술과 기법 을 말한다. 본 연구에서는 사업의 성공적 수행 역량, 경쟁기업 보다 차별화된 경쟁력, 최고 품질의 제품공 급을 위한 기술력 보유 등 3 개 문항으로 측정하였다.

(5) 구성원: 기업의 인력구성, 구성원의 능력, 전문성, 가치 관 및 그들의 행동패턴을 의미한다. 본 연구에서는 미 래발전에 필요한 인재보유, 역량개발을 위한 투자, 업 무수행에 필요한 역량보유, 필요한 인적자원 보유 등 4 개 문항으로 측정하였다.

(6) 제도 및 시스템: 기업경영의 의사결정과 운영에 틀이 되는 관리제도와 절차 등의 각종 시스템을 말한다. 본 연구에서는 계획의 수립, 조정, 통제 및 성과측정 등의 제도와 조직이 잘 갖추어짐, 사업수행 관련 제도 및 시 스템 잘 갖추어짐, 인사관련 제도 및 시스템이 잘 갖추 어짐, 성과보상 시스템 잘 갖추어짐, 업무수행을 위한 정보시스템의 구비 정도 등 5 개 문항으로 측정하였다.

(7) 공유가치: 공유가치는 기업문화에 있어서 가장 중요한 구성요인으로 구성원 모두가 공동으로 소유하고 있는 가치관과 이념 그리고 기업의 기본목적 등을 말한다. 본 연구에서는 공유가치가 명확한지, 공유가치를 인식 하고 있는지, 공유가치를 실현하는지 등 3 개 문항으로 측정하였다.

\subsection{2 조직유효성}

(1) 직무몰입 : 직장에 대한 소속감과 자긍심을 통해 개인 적인 감정으로 우러나며 직무에 대한 헌신, 및 공헌의 정도를 의미하는 것으로 직장에 대한 자긍심, 소속감 및 입사 후회 안함 등 4 개 문항으로 측정하였다.

(2) 직무만족 : 직무만족은 조직구성원이 자신의 직무에 대 한 유쾌하고 긍정적인 정서상태로 보수, 복지후생, 승 진 등의 위생요인과 업무 자율성, 인정, 성취감의 동기 요인으로 구성된 6 개 문항으로 측정하였다.

(3) 조직융합성 : 통합 기업에 가장 필요한 항목으로서 조 직융합을 이루었을 때 통합된 성과를 나타낼 수 있다. 조직과의 일체감, 직원간의 유대관계 등 일종의 정서 적 감정으로 본 연구에서는 주요 의사결정에 통합이전 출신 반반씩 참여치 않으면 불안, 업무추진시 출신소 속 의식, 가치나 이념차이로 혼란을 느낌 등 3 개 문항 으로 측정하였다.

\section{표 1. 분석 대상의 일반적 특성}

\begin{tabular}{|c|c|c|c|}
\hline \multicolumn{2}{|c|}{ 구 분 } & 빈도 & $\%$ \\
\hline \multirow{2}{*}{ 성별 } & 남 & 939 & 88.3 \\
\hline & 여 & 124 & 11.7 \\
\hline \multirow{6}{*}{ 근속년수 } & 1 5년 & 246 & 23.1 \\
\hline & 6 10년 & 180 & 16.9 \\
\hline & 11 15년 & 107 & 10.1 \\
\hline & 16 20년 & 279 & 26.2 \\
\hline & 21 25년 & 168 & 15.8 \\
\hline & 26년 이상 & 83 & 7.8 \\
\hline \multirow{7}{*}{ 직급 } & 1 급 & 33 & 3.1 \\
\hline & 2 급 & 141 & 13.3 \\
\hline & 3 급 & 268 & 25.2 \\
\hline & 4,5 급 & 525 & 49.4 \\
\hline & 6 급 & 33 & 3.1 \\
\hline & 7급 & 26 & 2.4 \\
\hline & 기타 & 37 & 3.5 \\
\hline \multirow{2}{*}{ 합병 전 소속 } & A 소속 & 434 & 40.8 \\
\hline & $\mathrm{B}$ 소속 & 629 & 59.2 \\
\hline \multicolumn{2}{|c|}{ 합 } & 1063 & 100.0 \\
\hline
\end{tabular}

\section{4. 실증분석}

\section{1 조사의 개요}

본 연구에서는 공기업 선진화 정책에 의거 2개 공기업이 통합되어 지난 2009년 10월에 출범한 공기업으로서 6개월 이상 조직융합과 합병후 통합과정이 진행된 조직구성원들을 대상으로 설문조사를 실시하였다. 조사대상 추출은 비례적 유의할당추출법으로 이루어졌으며, 조사대상자에게 직접 메 일을 발송하여 응답하도록 한 웹메일을 이용한 자기기입식 응답방식을 사용하였다. 그리고 2000 명에게 설문을 배포하 여 그 중 1,063 부를 회수하여 실증분석을 실시하였다. 본 연 구에서 실증분석을 위해 수집된 데이터의 특성을 살펴보면 표 1 과 같다.

\section{2 변수의 타당성 및 신뢰도 검증}

본 연구의 변수들을 측정하기 위하여 사용된 측정항목의 내 용은 선행연구를 바탕으로 특정기업의 특성에 맞게 구성하였 다. 변수의 타당성 검증을 위한 요인분석 결과는 표 2 와 같다.

먼저, 기업문화 구성요소에 대한 분석결과를 보면 구성원 변수의 역량개발투자 항목은 제도 및 시스템 요인에, 역량보 유와 인적자원보유 항목은 사업능력 및 기술력 요인으로 묶 여있다. 이는 역량개발투자 항목은 제도에 가까운 내용이고, 사업능력과 기술력에 대한 요인은 결국 구성원의 역량과 필 요한 인적자원이 필요한 내용이기 때문에 비슷한 성격을 갖 는 요인 유형으로 묶인 것으로 판단된다. 6 개 요인의 고유치 


\section{표 2. 기업문화 구성요소의 회전된 행렬}

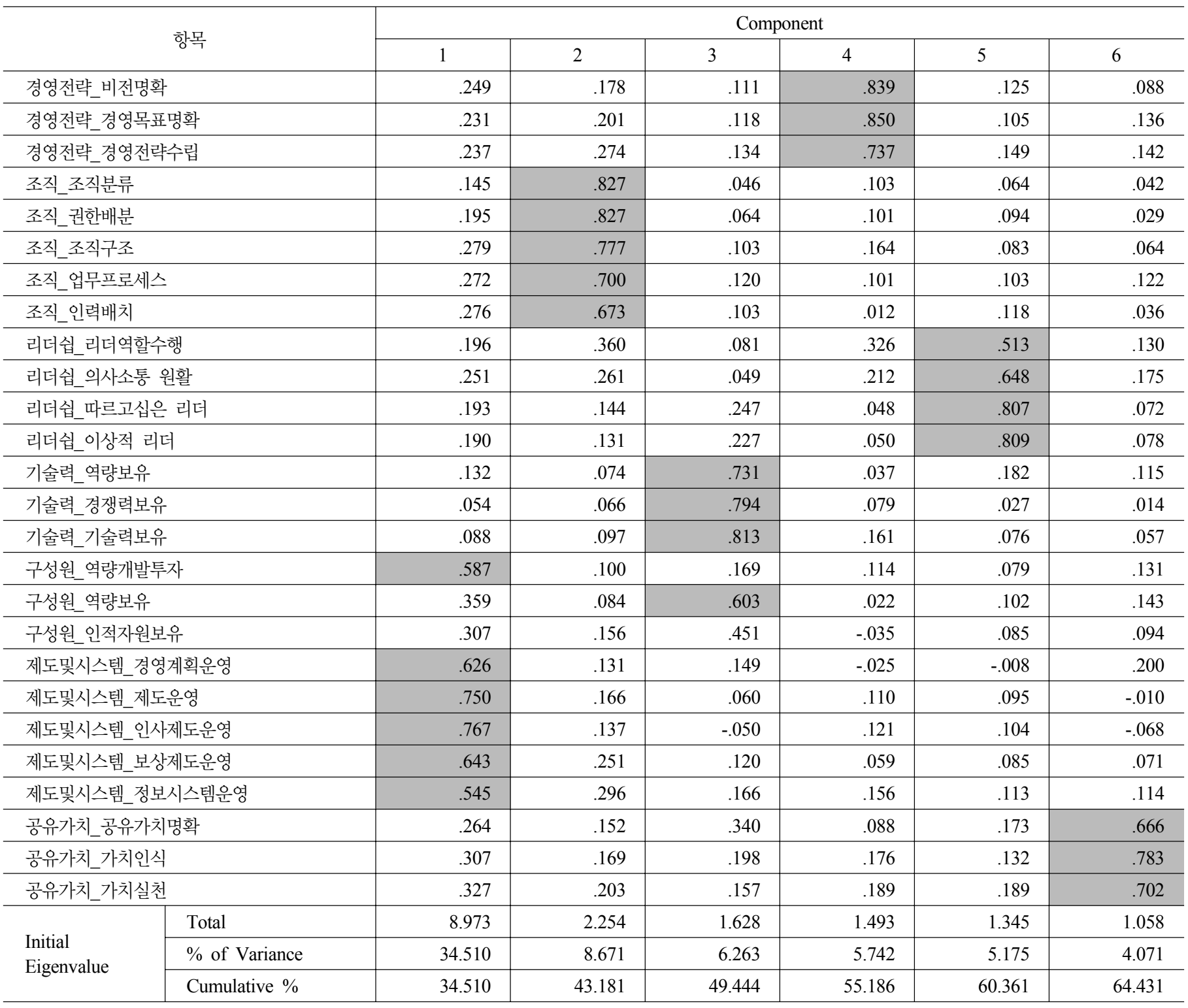

Extraction Method: Principal Component Analysis.

Rotation Method: Varimax with Kaiser Normalization.

a Rotation converged in 6 iterations.

는 모두 1 이상으로 나타났으며, 이들 요인은 전체 변량의 $64.43 \%$ 를 설명하고 있는 것으로 나타나 독립된 요인으로 간 주할 수 있다. 이에 본 연구에서는 기업문화 구성요소는 총 6 개로 구분하고자 한다.

기업문화 구성요소의 요인은 다음과 같이 명명한기로 한 다. 첫째 요인은 제도 및 시스템 요인으로 명명한다. 둘째 요 인은 조직요인으로 명명한다. 셋째 요인은 사업능력 및 기술 력 요인으로 명명한다. 넷째 요인은 경영전략 요인으로 명명 한다. 다섯째 요인은 리더쉽 스타일 요인으로 명명한다. 여섯 째 요인은 공유가치 요인으로 명명한다.

다음으로 조직유효성에 대한 요인분석 결과는 표 3 과 같
다. 분석결과를 살펴보면 직무만족의 성취감 항목이 직무몰 입 요인에 더 유사한 특성을 갖는 항목으로 나타났으나 총 3 개 요인으로 분류되었다. 그리고 3 개의 고유치는 모두 1 이상 으로 나타났으며, 이들 요인은 전체 변량의 $58.08 \%$ 를 설명하 고 있는 것으로 나타나 독립된 요인으로 간주할 수 있다. 조 직유효성 요인은 다음과 같이 명명한다. 첫째 요인은 직무몰 입요인으로 명명한다. 둘째 요인은 직무만족 요인으로 명명 한다. 셋째 요인은 조직융합 요인으로 명명한다.

측정도구의 신뢰도를 검증하기 위하여 자료의 내적 일관 성을 나타내는 Cronbach's a 값을 이용하였는 바 그 결과는 표 4 와 같다. 분석결과로 나타난 각 하위계수별 신뢰도 계수 
표 3. 조직유효성 변수의 회전된 행렬

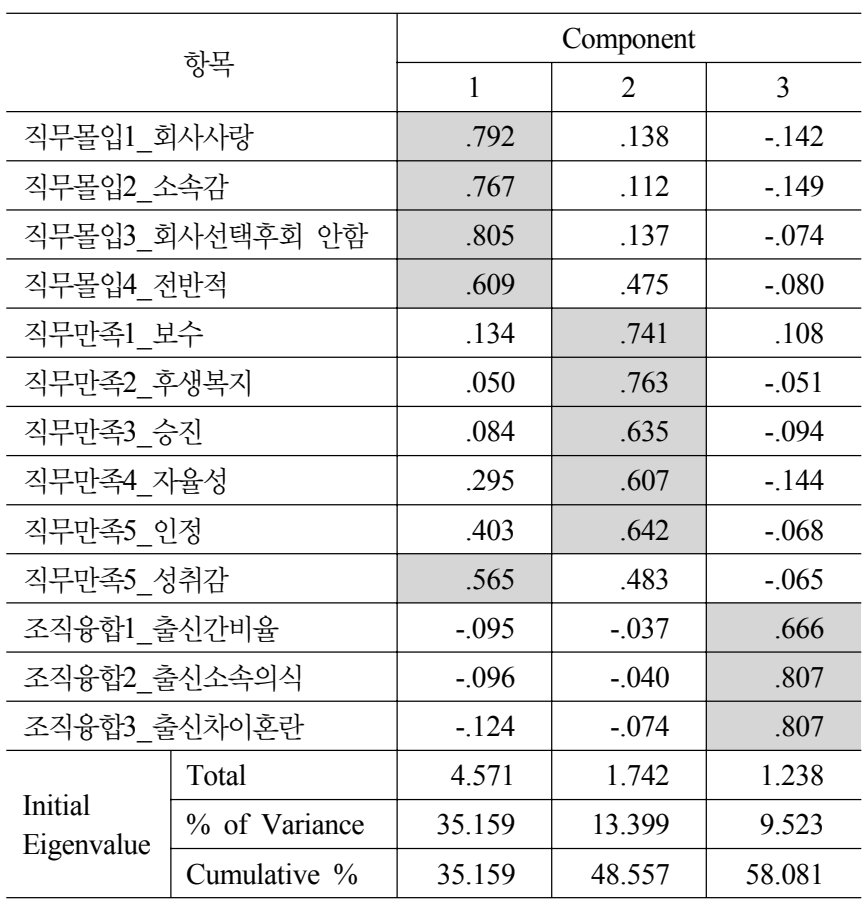

Extraction Method: Principal Component Analysis.

Rotation Method: Varimax with Kaiser Normalization.

a Rotation converged in 5 iterations.

\section{표 4. 측정항목 신뢰도 분석}

\begin{tabular}{c|l|c|c}
\hline \multicolumn{2}{|c|}{ 요인 } & $\begin{array}{c}\text { 신뢰계수 } \\
\text { (Cronbach's a) }\end{array}$ & 문항 수 \\
\hline \multirow{4}{*}{$\begin{array}{c}\text { 기업문화 } \\
\text { 구성요소 }\end{array}$} & 경영전략 & .890 & 3 \\
\cline { 2 - 4 } & 조직구조 & .875 & 5 \\
\cline { 2 - 4 } & 리더십 스타일 & .816 & 4 \\
\cline { 2 - 4 } & 사업능력과 기술력 & .773 & 5 \\
\cline { 2 - 4 } & 제도와 시스템 & .795 & 5 \\
\cline { 2 - 4 } & 공유가치 & .840 & 3 \\
\hline \multirow{2}{*}{} & 직무몰입 & .826 & 5 \\
\hline & 직무만족 & .757 & 5 \\
\hline & 조직융합 & .664 & 3 \\
\hline
\end{tabular}

를 확인해보면 조직융합만이 .664로 나타났으며, 기타 다른 척도들은 .7 이상으로 신뢰도계수가 합당한 수준에 이르고 있 다고 볼 수 있다. 즉, 전반적으로 .7 이상 높게 나타나 내적 일 관성이 있는 척도라고 할 수 있다.

\section{3 가설 검증}

\subsection{1 가설 1 의 검증}

기업문화 구성요소가 직무몰입에 미치는 영향을 분석하기 위해 다중회귀분석을 실시한 결과, 회귀모형의 검정통계량이 유의미한 것으로 나타났다 $(\mathrm{F}=57.232, p<0.01)$. 각각의 구성요
표 5. 기업문화 구성요소가 직무몰입에 미치는 영향

\begin{tabular}{|c|c|c|c|c|c|c|c|}
\hline $\begin{array}{l}\text { 종속 } \\
\text { 변수 }\end{array}$ & 독립변수 & $\mathrm{R}^{2}$ & $\mathrm{~F}$ & 유의도 & Beta & $\mathrm{t}$ & 유의도 \\
\hline \multirow{7}{*}{$\begin{array}{l}\text { 직무 } \\
\text { 몰입 }\end{array}$} & (Constant) & \multirow{7}{*}{.245} & \multirow{7}{*}{57.232} & \multirow{7}{*}{$.000 * *$} & & .000 & 0.000 \\
\hline & 제도 및 시스템 & & & & 0.143 & 5.333 & $0.000 * *$ \\
\hline & 조직구조 및 운영 & & & & 0.113 & 4.233 & 0.000 ** \\
\hline & $\begin{array}{l}\text { 사업능력 및 } \\
\text { 기술력 }\end{array}$ & & & & 0.357 & 13.372 & $0.000 * *$ \\
\hline & 경영전략 & & & & 0.112 & 4.197 & $0.000^{* *}$ \\
\hline & 리더쉽스타일 & & & & 0.215 & 8.035 & $0.000 * *$ \\
\hline & 공유가치 & & & & 0.160 & 6.004 & $0.000 * *$ \\
\hline
\end{tabular}

$* * p<0.01, * p<0.05$

소를 통하여 직무몰입을 설명할 수 있는 비율인 설명력 $\left(\mathrm{R}^{2}\right)$ 은 $0.245(p<0.01)$ 으로 나타났다.

기업문화 구성요소 중 직무몰입에 미치는 영향력이 유의 미한 결과를 보인 것은 제도 및 시스템 $(\mathrm{t}=5.333, p<0.01)$, 조직 구조 및 운영 $(\mathrm{t}=4.233, p<0.01)$, 사업능력 및 기술력 $(\mathrm{t}=13.372$, $p<0.01)$, 경영전략 $(\mathrm{t}=13.372, p<0.01)$,리더쉽 스타일 $(\mathrm{t}=4.197$, $p<0.01)$, 공유가치 $(\mathrm{t}=6.004, p<0.01)$ 로 측정한 모든 요인이 영 향을 미쳤다. 이에 따라 직무몰입에 대하여 기업문화 모든 구 성요소가 긍정적인 영향을 미친다는 것을 알 수 있다. 이 중 Beta 값을 기준으로 볼 때 사업능력 및 기술력이 상대적으로 가장 큰 영향을 미치며, 다음으로는 리더쉽 스타일이 큰 영향 을 미치는 요인으로 볼 수 있다. 따라서 합병기업 구성원들의 직무몰입을 향상시키기 위해서는 우선적으로 고려해야 할 것 이 사업능력 및 기술력에 대한 요인이며, 다음으로 리더쉽 스 타일, 공유가치 등에 대한 개선이 있어야 할 것이다. 따라서 기업문화 구성요소별로 구성원의 직무몰입에 상이한 영향을 줄 것이라는 가설 1 은 채택되었다고 볼 수 있다.

\subsection{2 가설 2 의 검증}

기업문화 구성요소가 직무만족에 미치는 영향을 분석하기 위해 다중회귀분석을 실시한 결과, 회귀모형이 유의미한 것 으로 나타났다 $(\mathrm{F}=56.978, p<0.01)$. 각각의 구성요소를 통하 여 직무만족을 설명할 수 있는 비율인 설명력 $\left(\mathrm{R}^{2}\right)$ 은 0.245 $(p<0.01)$ 로 나타났다.

기업문화 구성요소 중 직무만족에 미치는 영향력이 유의 미한 결과를 보인 것은 제도 및 시스템 $(\mathrm{t}=15.443, p<0.01)$, 조 직구조 및 운영 $(\mathrm{t}=6.370, p<0.01)$, 사업능력 및 기술력 $(\mathrm{t}=1.974$, $p<0.05)$, 경영전략 $(\mathrm{t}=3.919, p<0.01)$, 리더쉽 스타일 $(\mathrm{t}=6.583$, $p<0.01)$ 로 나타나, 직무몰입에 대하여 상기의 기업문화 구성 요소가 긍정적인 영향을 미친다는 것을 알 수 있다. 이 중 Beta 값을 볼 때 제도 및 시스템이 가장 큰 영향을 미치는 것 으로 볼 수 있다. 다음으로는 리더쉽 스타일, 조직구조 순이 다. 따라서 합병기업 구성원들의 직무만족을 향상시키기 위 
표 6. 기업문화 구성요소가 직무만족 미치는 영향

\begin{tabular}{|c|c|c|c|c|c|c|c|}
\hline $\begin{array}{l}\text { 종속 } \\
\text { 변수 }\end{array}$ & 독립변수 & $\mathrm{R}^{2}$ & $\mathrm{~F}$ & 유의도 & Beta & $\mathrm{t}$ & 유의도 \\
\hline \multirow{7}{*}{$\begin{array}{l}\text { 직무 } \\
\text { 만족 }\end{array}$} & (Constant) & \multirow{7}{*}{.245} & \multirow{7}{*}{56.978} & \multirow{7}{*}{$.000 * *$} & & .000 & 0.000 \\
\hline & 제도 및 시스템 & & & & 0.413 & 15.443 & $0.000 * *$ \\
\hline & 조직구조 & & & & 0.170 & 6.370 & $0.000^{* *}$ \\
\hline & $\begin{array}{c}\text { 사업능력 및 } \\
\text { 기술력 }\end{array}$ & & & & 0.053 & 1.974 & $0.049 *$ \\
\hline & 경영전략 & & & & 0.105 & 3.919 & $0.000 * *$ \\
\hline & 리더쉽스타일 & & & & 0.176 & 6.583 & $0.000^{* *}$ \\
\hline & 공유가치 & & & & 0.012 & .458 & 0.647 \\
\hline
\end{tabular}

$* * p<0.01, * p<0.05$

해서는 가장 우선적으로 제도 및 시스템에 대한 개선이 있어 야 한다는 것을 알 수 있다. 이는 승진, 성과측정 및 보상, 복 지후생 등 제도적 차원의 개선이 중요함을 시사한다.

한편, 기업문화 구성요인 중 공유가치는 직무만족에 유의 미한 영향력을 미치지 않는 것으로 나타난다. 이렇게 나타나 는 이유는 제도나 조직구조 등의 요인들은 합병 후 $\mathrm{PMI}$ 작업 을 통해 이미 통합작업이 어느 정도 진행되었으나, 공유가치 형성은 장기간이 소요되는 바 현재 통합 초기단계로서 아직 형성되지 않았기 때문에 나타난 결과로 해석할 수 있다.

따라서 기업문화 구성요소별로 구성원의 직무만족에 상이 한 영향을 줄 것이라는 가설 2는 채택되었다고 할 수 있다.

\subsection{3 가설 3 의 검증}

기업문화 구성요소가 조직융합에 미치는 영향을 분석하기 위해 다중회귀분석을 실시한 결과, 회귀모형이 유의미한 것 으로 나타났다 $(\mathrm{F}=22.104, p<0.01)$. 각각의 구성요소를 통하여 조직융합을 설명할 수 있는 설명력 $\left(\mathrm{R}^{2}\right)$ 은 $0.112(p<0.01)$ 로 나 타났다.

기업문화 구성요소 중 조직융합에 미치는 영향력은 사업 능력 및 기술력 $(\mathrm{t}=1.556)$ 을 제외하고 모두 유의미한 것으로 나타났다. 회귀계수가 모두 음의 값을 갖는 이유는 조직융합 측정항목이 사업능력과 기술력을 제외하고는 부정형 질문으 로 구성되어 나타난 결과로 해석된다. 즉, 기업문화 구성요소 가 잘 이루어질수록 조직융합의 부정적 요소가 줄어들게 하 는 효과가 있는 것을 의미하는 것으로 값이 작을수록 조직유 효성에 긍정적인 긍정적인 영향을 미친다는 의미이다.

이 중 Beta 값을 볼 때 리더쉽 스타일이 가장 큰 영향을 미 치고 있고, 다음으로 공유가치, 조직구조 순이다. 따라서 합병 기업 구성원들의 조직융합을 향상시키기 위해서는 가장 우선 적으로 리더쉽을 발휘하여 부하직원들을 융합시키는 것이 필 요하며 공유가치를 통합시켜 동일한 회사에 대한 동일한 가 치관과 목표를 갖도록 하는 것도 중요하다는 것을 시사한다.

한편, 조직융합은 조직차원의 변수로서 개인이 향상시키기 도 하지만 조직 전체적으로 고려되고 향상시켜야 할 변수이
표 7. 기업문화 구성요소가 조직융합에 미치는 영향

\begin{tabular}{|c|c|c|c|c|c|c|c|}
\hline $\begin{array}{l}\text { 종속 } \\
\text { 변수 }\end{array}$ & 독립변수 & $\mathrm{R}^{2}$ & $\mathrm{~F}$ & 유의도 & Beta & $\mathrm{t}$ & 유의도 \\
\hline \multirow{7}{*}{$\begin{array}{l}\text { 조직 } \\
\text { 융합 }\end{array}$} & (Constant) & \multirow{7}{*}{.112} & \multirow{7}{*}{22.104} & \multirow{7}{*}{$.000^{* *}$} & & .000 & 0.000 \\
\hline & 제도 및 시스템 & & & & -0.413 & -2.309 & $0.021^{*}$ \\
\hline & 조직구조 & & & & -0.170 & -4.085 & $0.000 * *$ \\
\hline & $\begin{array}{c}\text { 사업능력 및 } \\
\text { 기술력 }\end{array}$ & & & & 0.053 & 1.556 & 0.120 \\
\hline & 경영전략 & & & & -0.105 & -5.654 & $0.000 * *$ \\
\hline & 리더쉽스타일 & & & & -0.176 & -7.687 & $0.000^{* *}$ \\
\hline & 공유가치 & & & & -0.012 & -4.139 & $0.000^{* *}$ \\
\hline
\end{tabular}

$* * p<0.01, * p<0.05$

다. 기업문화 구성요소 중 사업능력 및 기술력 요인을 제외한 다른 요인들은 조직융합 차원에서 볼 때 개인이 향상시켜야 하기 보다는 조직 전체적으로 고려되어야 할 요인들인 반면, 사업능력 및 기술력 요인은 개인적으로 향상시키는 요인이기 때문에 조직융합에 직접적인 영향을 미치지 않는 것으로 판 단된다.

따라서 기업문화 구성요소별로 구성원의 조직융합에 상이 한 영향을 줄 것이라는 가설 3 도 채택되었다고 볼 수 있다.

이상에서 기업문화의 각 구성요소가 조직유효성에 미치는 영향을 다중회귀분석을 통해 살펴보았다. 이를 종합해 보면 조직유효성에 기업문화 구성요소가 영향을 미치는 요인은 각 각 종속변수마다 상이하다는 것을 알 수 있으며, 이를 통해 볼 때 조직유효성의 특성에 따라 기업문화 구성요소를 차별 적으로 개선해야 한다는 것을 시사한다. 또한 기업문화 구성 요소는 기업성과에 긍정적인 영향을 미치는 것을 통계적으로 입증하고 있는 것으로 볼 수 있다.

\section{5. 결 론}

결론적으로 합병기업의 기업문화 구성요소는 조직유효성 에 중요한 영향을 미치는 변수라고 할 수 있다. 본 연구는 합 병기업의 기업문화 및 구성요소 그리고 이에 따른 조직유효 성에 관한 선행연구를 근거로 개념적 연구모형을 수립하고, 이의 타당성을 검증하기 위하여 합병기업의 기업문화 구성요 소와 조직유효성의 관련성에 관한 연구가설을 설정하였다. 가설검증을 위한 주된 분석방법은 다중회귀분석으로서 분석 결과를 통한 시사점을 요약하면 다음과 같다.

첫째, 기업문화 구성요소 관리의 중요성이다. 기업문화 구 성요인이 조직유효성에 미치는 영향에 대한 회귀분석 결과는 조직유효성 요인에 따라 차이는 있지만 기업문화의 모든 구 성요인들이 유의미한 결과를 보여주고 있다. 즉, 조직유효성 을 향상시키기 위해서는 어느 한 가지 요인이 아니라 기업문 화를 구성하는 요인을 모두 고려하여야 한다는 의미이다. 특 히, 통합 관점에서 볼 때 기업문화 구성요소의 관리는 중요성 
이 더 크다고 볼 수 있다.

둘째, 기업문화 구성요인이 $\mathrm{PMI}($ 합병후 통합작업)에서 우 선순위를 제시하고 있다. 우선 직무몰입을 향상시키기 위해 서는 사업능력 및 기술력을 향상시키기 위한 교육훈련 등에 대한 우선순위를 두어야 한다는 것을 시사하며, 다음으로 직 무만족을 향상시키기 위해서는 제도 및 시스템의 통합이 중 요하다는 것을 시사하고 있다. 또한 조직융합을 증가시키기 위해서는 리더쉽 발휘와 공유가치의 통합이 중요함을 시사하 고 있다. 조직융합에 미치는 영향에 공유가치가 상대적으로 높은 영향력을 갖는 이유는 그만큼 조직융합에 있어서 공유 가치의 중요도가 크다는 것이다. 기업문화 구성요인 중 공유 가치는 기업문화를 처음 개발하거나 혁신적으로 변화시킬 때 에 큰 힘을 발휘한다는 것이 학자들의 견해를 뒷받침하는 결 과로 볼 수 있다.

셋째, 합병기업에서 조직융합은 중요한 의미를 부여한다. 기업문화 구성요인이 조직융합에 미치는 영향에 대한 회귀분 석 결과로서, 기업문화의 구성요인 중 사업능력 및 기술력을 제외한 모든 요인들이 유의미한 결과를 보여주고 있다. 즉, 합병기업 구성원들의 조직융합을 위해서는 어느 한 가지 요 인이 아니라 경영전략, 조직, 리더쉽, 제도 및 시스템, 특히 공유가치 등의 구성요인을 고려하여야 한다는 의미이다. 조 직융합은 다른 의미로는 문화통합으로도 볼 수 있는바, 한편 으로는 합병기업에서 문화통합을 이루기 위해서는 상기의 요 인들에 대한 개선방안을 제시하여야 한다는 것을 시사한다.

이러한 결과들을 볼 때 기업에서 기업문화 구성요인은 조 직유효성을 향상시키려 할 때 어느 한 가지도 소홀히 할 수 없는 요인임을 시사하고 있다. 특히, 합병기업의 경우는 문화 적 통합을 통해 조직융합을 이루어야 하기 때문에 조직유효 성을 향상시키기 위해서는 기업문화의 구성요인에 대한 고려 는 일반적인 기업보다 더 필요할 수도 있다. 선행연구에서도 합병기업에서 문화적 적합성 부족으로 조직융합이 안된 경우 수익률이 낮아진다는 것을 입증한 결과를 보면 본 연구의 결 과와 일맥상통하다고 볼 수 있다.

본 연구는 Pascale과 Athos 및 Peters와 Waterman의 이론 적 모형에 근거하여 아직까지 시도하지 않았던 기업문화 구 성요인이 조직유효성에 미치는 영향을 실증적으로 검증한 탐 색적 연구라는데 그 의의가 있다고 하겠다. 다만 본 연구는 다음과 같은 면에서 연구의 한계를 갖는 다. 첫째, 최근에 합 병된 특정 공기업만을 대상으로 실증분석을 하였기 때문에 민간기업을 포함한 모든 합병기업의 현상에 대한 설명과 연 구결과의 적용에는 한계가 있을 수 있다. 둘째, 기업문화 구 성요소와 조직유효성 변수와의 다중회귀분석시 통제변수를 고려하지 않았다. 즉 기업문화 구성요소가 조직유효성에 영 향을 미칠 때 제 3 의 매개변수가 개입될 경우 영향정도가 높 거나 낮아질 수 있다는 점에서 연구결과의 해석에 있어 일부 한계를 갖는다. 또한 본 연구에서는 리더십스타일을 기업문
화 구성요소 중 하나로 구분하였으나 통상 합병후 통합과정 에서 $\mathrm{CEO}$ 의 의지가 기업문화 구성요소의 통합에 미치는 영 향이 크다는 점에서 리더십스타일 혹은 $\mathrm{CEO}$ 의 리더십을 매 개변수로 설정하여 향후 연구과제에서 그 영향정도를 규정하 는 것도 필요할 것으로 판단된다.

\section{참고문헌}

1. 강정애(1997), 조직문화적 특성에 따른 조직성과에 관한 연구, 경영학연구 제 26 권 제 3 호, 513-530.

2. 고종식(1999), 기업문화 유형과 조직 유효성에 관한 연구, 산업 경영연구 제 12 권 제5호, $15-31$.

3. 김세영(1990), 조직문화와 리더쉽, 교보문고.

4. 딜로이트컨설팅코리아(역)(2006), 기업문화 혁신전략, E. H. Schein의 The Corporate Culture Survival Guide, 일빛.

5. 민경호·이병석(2005), 조직구성원들이 인식한 $\mathrm{CEO}$ 리더쉽스타 일이 조직효과성에 미치는 영향, 대한경영학회지, 18, 1. 5-6.

6. 박경문·최명범(2001), 합병기업의 조직문화 통합에 따른 리더 역할이 조직유효성에 미치는 영향, 인적자원관리연구, 제 2 호, 147-169.

7. 박경문·최명범(2002), 합병기업의 조직문화가 조직유효성 및 노사관계에 미치는 영향, 인적자원관리연구, 제4호, 215-243.

8. 박민생(2006), 기업문화 개발의 활동이 조직성과에 미치는 영향 연구, 인적자원관리연구, 제13권 제2호, 69-86.

9. 신유근(1985), 기업문화와 조직성과, 경영논집, 19.3 , 서울대 경 영연구소.

10. 이학종(2008), 기업문화와 기업경쟁력: 한국의 기업문화와 경쟁 력 강화를 위한 새 기업문화 개발, 박영사.

11. 황성돈 외(2008), 조직융합관리 표준모델 개발, 한국행정학회.

12. Campbell, J. P. (1977). On the nature of organizational effectiveness. New perspectives on organizational effectiveness, 13-55

13. Cray, D. and Mallory, G. R. (1998). Making Sense of Managing Culture. ITP.

14. Deal, T.E. \& Kennedy, A.A. (1982), Corporate Culture: The Rites and Rituals of Corporate Life, Addison-Wesley, 4-5.

15. Denison, R. Daniel \& Mishra, Aneil K.(1995), Toward a Theory of Organizational Culture and Effectiveness, Organization Science, Vol.6, No.2, 204-223.

16. Harrison, R. (1972), Understanding Your Organization's Culture, Harvard Business Review, 50. 3, 119-128.

17. Pascale, R. T. and Athos, A. G. (1981), The Art of Japanese Management, New York, Penguin Books.

18. Peters, T. J. \& Waterman, R. H. (1982), In Search of Excellence, New York: Harper and Row.

19. Schein, E. H. (2004), Organizational Culture and Leadership, Jossey-Bass.

20. Schweiger, D. M. and Weber, Y. (1993). Strategies for Managing Human Relations Ruling Mergers and Acquisitions. Human Resource Planning. 12(2).

21. Sorensen, Jesper B. (2002),The Strength of Corporate Culture and the Reliability of Firm Performance, Administration Science Quarterly, Vol.47, No.1, 70-90.

22. Steers, R. M. (1975). Problems in the measurement of organizational effectiveness. Administrative Science Quarterly, 20(4), 546-558. 